THE GENERAL MEDICAL COUNCIL AND THE "L.S.A."

A proshoution by the General Medical Council came before the Petty Sessional Court at Caxton, Cambridgeshire, on April 6th, in which a medical man was charged with wilfully and falsely pretending to use the name and title of physician and surgeon contrary to Act 21 Vict. c. 90, sect. 40 , and Acts amending the same. The defendant was Mr. Herbert Kingsley Hunter, of Montague House, Gamlingay, Cambridgeshire, who a few years ago acquired the practice formerly carried on for many years by Dr. Trimmer.

Mr. Muir Mackenzie, barrister, instructed by $\mathbf{M r}$. $\mathbf{H}$. Farrer, of Lincoln's Inn-fitds, appeared for the General Medical Council, whose solicitor, Mr. F. W. Farrer, had laid the information, and Mr. Horace Condy, barrister, instructed by Messrs. Berkeley, Son, and Hains, of Lincoln's Innfields, appeared for the defendant.

Mr. MUIR MACKENZIE, in opening the case for the prosecution, said the facts were not in dispute. Mr. Hanter, the defendant, was an American citizen who came over to this country to practise, and in November, 1893, obtained the degree or qualification of a Licentiate of the Society of Apotbecaries of London and was registered as such. That was the only English qualification which Mr. Hunter possessed, but he claimed to possess, and no doubt right'y, an American degree of Doctor of Medicine (Philadelphia). In his practice be assumed, and to do him jastice he claimed the right to assume in this country, the title of "M.D." and also stphysician and surgeon." The General Medical Council warned $\mathrm{Mr}$. Hunter that he was practising under a title which he did not possess. In reply Mr. Hunter asserted that he had a right to do so and therefore this was not a case of assuming a title inadvertently or through ignorance. It had been decided by the courts of law, in the case of Regina $v$. Baker, that a medical practitioner who was a Licentiate of the Society of Apothecaries and bad no other registered title had no right to practise under the title of "physician and surgeon" or "M.D.," but had the right to practise under the title only which he did possess-viz., that of "L.S A" To show that Mr. Hunter took the course he had done in order to assert his right he (Mr. Mackenzie) read some letters which had passed between Mr. Hunter and the General Medical Council in the last of which the defendant wrote to the Council: "I shall not trouble you further with any questions, but as I am backed up I mean to fight now to the end." In conclusion he (Mr. Mackenzie) should call evidence to show that Mr. Hanter did use the titles of physician and surgeon when it was perfectly clear that he was not entitled to do so. If Mr. Hunter claimed to do it under the diploma of the Society of Apothecaries or the American degree, then the law had held by the decision in the Aston case that he was wrong, and he must ask the Bench to convict if they were satisfied that the defendant had used the titles of physician and surgeon. He then put in a copy of the Medical Register, which is made evidence by the statute, and called witnesses.

Mr. HerreRt William FARRer, of Lincoln's Inn, son of Mr. F. W. Farrer, solicitor to the General Medical Council, formally proved the receipt of the letters from Mr. Hunter to the Conncil and said Mr. Hunter was first warned that he must not use the title "M.D." and he asked if he could use physician and surgeon and was informed that the Council could not advise him.

Witnesses were called as to paying accounts to $\mathrm{Mr}$. Hunter, printing of bill-heads, \&c., in which he described thimself as "M.D.," and as "L.S.A., physician and surgeon."

Mr. Condr, for the defence, said the title "M.D." had nothing to do with this case and the case of the Queen $v$. Baker was for using "M.D."

Mr. MACKENGIE said it was also for using "physician and surgeon."

Mr. CONDY said the defendant did not claim the right to use the title of "physician and surgeon" by virtue of the American degree but by virtue of the diploma which he held from the Society of Apothecaries, which he (Mr. Condy) handed to the Court. In 1886 the Society of Apothecaries was empowered to grant diplomas entitling their holders to practise in medicine, eurgery, and midwifery and it was by virtue of that diploma, and by that alone, that Mr. Hunter claimed the right to use the title of " physician and surgeon." Upon his bill-heads he described himself as "L B.A., physician and surgeon," and it was of this that the prosecution complained. 'l'he M.D. degree was not before them at all. He submitted that "L.S.A., physician and surgeon," was an accurate description which could deceive no one, because "physician and surgeon" being prefixed by "Licentiate of the Society of Apothecaries" showed the right upon which he practised. The case of the Queen $v$. Baker tarned chitfly upon the M.D. degree and he referred to the case of Ellis $v$. Kelly in support of his view that the diploma gave the defendant the right to use "physician and surgeon "in connexion therewith. The correspondence put in showed that when Mr. Hunter was told that he could not use M.D. he ceased to use it; that he asked the General Medical Council if he conld call himself "physician and surgeon," and when they replied, "We cannot advise you," he did the reasonable thing of applying to the body under the diploma of which he was entitled to practise-the Society of Apothecaries. Their answer was that a "L.S A." could call himself by any title or titles denoting the right to practise in medicine, surgery, and midwifery providing that he did not assume titles conferred by another governing body or university. He therefore submitted that the defendant had the right to describe himself as he had done. If the magistrates were against him on that point then he submitted that before they could convict the defendant they must also make up their minds that he not only called himself that which in fact the law would not allow him to do, bat that he did so wilfully and in violation of the law and knowing that he had no right to do so. Lord Bramwell had held that the statute did not impose a penalty for incorrectness merely, but for assuming a title wilfally and falsely. The Act was intended to apply to unregistered men and he submitted that his client had a right to describe himself as he did and that they could not convict him of wilfally or falsely pretending to be that which he was not.

The Bench decided to convict upon the information for styling himself a "physician" and imposed a fine of $£ 5$ and costs. The second information for calling himself a "surgeon" was not proceeded with.

Mr. Condy asked the magistrates to state a case. It was important that this should be done both for the Society of Apothecaries and the General Medical Council. The matter must be fought out becanse the Society of Apothecaries must defend their diploma.

The magistrates saw no objection to a case being granted and it was understood that the necessary steps would be taken for carrying the case to a superior court.

\section{THIRD REPORT TO THE REGISTERED PRACTITIONERS OF ENGLAND AND WALES.}

LADIES AND GENTLEMEN,-The brief session of the General Medical Council which has just closed has been to a very gratifying extent productive of much good to the profession at large, not only in regard to the subject lald before the Council for its discussion-viz., the midwives egistration question-but also in establishing more firmly the principles of defensive medical legislation.

In the session of November last year the Council appointed a committee composed as follows: Sir Richard Thorne Thorne (chairman), Dr. Atthill, Dr. Glover, Dr. Cameron, Mr. Carter, Mr. Brown, and myself, to report upon any Bill bearing on the subject of midwives' registration that might be brought before Parliament and referred for criticism to the Conncil by the Government (Privy Council).

When Mr. J. B. Balfour's Bill was introduced and immediately obtained an early place in the ballot I wrote to the chairman and arged that the committee should be called together. After considerable opposition my request was acceded to. The committee met on three occasions and drew up a report, which bas just been published in extenso in the medical journals. This report was practically based upon the general principles formulated two years ago by the Midwives Bill Sub-committee of the Parliamentary Bills Committee of the British Medical Association. 
Of these principles the first and most fundamental is that the only possible method of arresting the notorious evils committed by miawives at the present time is to provide that an ignorant person who practises as a midwife for gain shall be punished. The second principle is that the trained midwife shall be limited to the attendance of cases of natural labour only, and shall tend as a nurse the mother and child during the lying-in period.

The third principle is that there shall be instituted a proper system of supervision and teaching of midwives or midwifery nurses by the medical profession. The report of the committee to the Council naturally met with obstruction in the committee from those members who are opposed to medical reforms but who did not venture in the Council itself to give expression to their antagonism.

All the principles of the committee's report were unanimously adopted by the Council and cast in the form of a memorandum (with wording adopted from the committee's report). This memorandum was directed to be sent to the President of the Privy Council as the Council's answer to a letter which had been received from him requesting the observations and opinions of the Council upon $\mathrm{Mr}$. J. B. Balfour's Bill.

Inasmuch as this memorandum of the opinions of the Council is, like the committee's report, a categorical condemnation of Mr. J. B. Balfour's Bill, nothing can be more satisfactory to the profession than the obtaining from the Council of a unanimous denunciation of a Bill which not only afforded no protection to the public, but seriously threatened the lawful rights of the registered medical practitioner. At the same time I wish to particularly draw the attention of the profession to a very important point involved in this decision-viz., that now the General Medical Council has officially accepted the principle laid down by the committee that no unqualified person should practise with impunity for gain. It necessarily follows as a logical sequence that this step in advance involves the support of the Council to future legislation which may be brough forward for the strengthening of the Medical Acts in this direction, and the earnestness of the feeling of the Council upon the matter was displayed in so unmistakeable a manner that the opposite view to which such strong expression has recently been given in the medical press, found upon this occasion absolutely no exponent.

April 12th, 1898.

VICTOR HORSLEY.

\section{VITAL STATISTICS.}

HEALTH OF RNGLISH TOWNG.

IN thirty-three of the largest English towns 6197 birth and 4352 deaths were registered during the week ending April 9th. The annual rate of mortality in these towns, which had been 20.2 and 21.5 per 1000 in the two preceding weeks, declined again last week to 20.2 . In London the rate was 19.6 per 1000 , while it averaged 20.7 in the thirty-two provincial towns. The lowest death-rates in these towns were 12.6 in Portsmouth, 14.1 in Oldham, 14.7 in West Ham, and 15.3 in Cardiff; the highest rates were 23.4 in Derby, 23.5 in Leeds, 23.7 in Plymouth, 25.6 in Salford, and 27.7 in Liverpool. The 4352 deaths in these towns included 516 which were referred to the principal zymotic diseases, against 550 and 538 in the two preceding weeks; of these, 234 resulted from measles, 125 from whoopingcough, 57 from diphtheria, 34 from "fever" (principally enteric), 33 from scarlet fever, and 31 from diarrhœea. The lowest death-rates from these diseases were recorded in Blackburn, Preston, Norwich, and Derby ; and the highest rates in Sheffield, Brighton, Bristol, Swansea, and Leicester. The greatest mortality from measles occurred in Brighton Swansea, Bristol, Leicester, Oldham, Halifax, and Sheffield from whooping-cough in West Ham, Bolton, and Salford and from "fever" in Burnley. "The mortality from scarlet fever showed no marked excess in any of the large towns. The 57 deaths from diphtheria included 29 in London, 3 in Cardiff, 3 in Bristol, 3 in Birmingham, and 3 in Leicester. One fatal case of small-pox was registered last week in Leeds and 1 in Gateshead, but not one in any other of the thirty-three large towns; and no smallpox patients were under treatment in any of the Metropolitan Asylums Hospitals on Baturday last, April 9th.
The number of scarlet fever patients in these hospitals and in the London Fever Hospital, which had been 2419,2371 , and 2377 at the end of the three preceding weeks, had further risen to 2421 on Saturday last ; 234 new cases were admitted during the week, against 255, 191, and 239 in the three preceding weeks. The deaths referred to diseases of the respiratory organs in London, which had been 402 and 451 in the two preceding weeks, declined again to 372 last week, and were 10 below the corrected average. The causes of 59 , or 1.4 per cent., of the deaths in the thirty-three towns were not certified either by a registered medical practitioner or by a coroner. All the causes of death were duly certified in Portsmouth, Nottingham, Salford, Bradford, and in ten other smaller towns; the largest proportions of uncertified deaths were registered in Leicester, Liverpool, Blackburn, Preston, and Sheffield.

\section{HEALTH OP MOOTOH TOWNB.}

The annual rate of mortality in the elght Bcotch towns, which had been 22.9 and 24.2 per 1000 in the two preced. ing weeks, declined to $24 \cdot 1$ during the week ending April 9th, but was 3.9 per 1000 above the mean rate during the same period in the thirty-three large Inglish towns. The rates in the eight Scotch towns ranged from 17.0 in Perth and 17.6 in Edinburgh to 26.3 in Glasgow and 31.9 in Dundee. The 728 deaths in these towns included 44 which were referred to whooping-cough, 24 to measles, 20 to diarrhcea, 9 to diphtheria, 4 to "fever," and 4 to scarlet fever. In all, 105 deaths resulted from these principal zymotic diseases, against 73 and 82 in the two preceding weeks. These 105 deaths were equal to an annual rate of 3.5 per 1000 , which was 1.1 above the mean rate last week from the same diseases in the thirtythree large English towns. The fatal cases of whooping cough, which had been 25 and 21 in the two preceding weeks, rose again to 44 last week, of which 31 occurred in Glasgow, 4 in Paisley, 3 in Aberdeen, and 3 in Edinburgh. The 24 deaths referred to measles exceeded by 1 the number in the preceding woek, and included 21 in Glasgow. The fatal cases of diphtheria, which had been 3 and 4 in the two preceding weeks, further rose to 9 last week, of which 2 occurred in Glasgow, 2 in Aberdeen, and 2 in Greenock. The 4 deaths referred to different forms of "fever" included 2 in Glasgow and 2 in Fdinburgh; and of the 4 fatal cases of scarlet fever 3 were recorded in Glasgow. The deathe referred to diseases of the respiratory organs in these towns, which had been 175 and 178 in the two preceding weeks, declined to 157 last week, but slightly exceeded the number in the corresponding period of last year. The causes of 36 , or nearly 5 per cent., of the deaths in these eight towns last week were not certified.

HWALTH OF DUBLIN.

The death-rate in Dublin, which had been 29.5 and $35-1$ per 1000 in the two preceding weeks, declined again to 24.3 during the week ending April 9th. During the thirteen weeks of last quarter the death-rate in the city averaged 32.4 per 1000 , the rate during the same period being 21.7 in London and 20.3 in Edinburgh. The 163 deaths registered in Dublin during the week under notice showed a decline of 72 from the number in the preceding week, and included 9 which were referred to the principal zymotic diseases, against 11 and 20 in the two preceding weeks ; of these, 3 resulted from different forms of "fever," 2 from diphtheria, 2 from whooping-congh, and 2 from diarrhcea, but not one from measles, scarlet fever, or smallpox. These 9 deaths were equal to an annual rate of 1.3 per 1000, the zymotic death-rate during the same period being 2.8 in London and 1.8 in Edinburgh. The deaths referred to "fever," which had declined from 7 to 4 in the three preceding weeks, further fell to 3 last week. The fatal cases of whooping-cough, which had been 3 and 5 in the two preceding weeks, declined again to 2 last week. The mortality from diphtheria and from diarrhcea also showed a decline from that recorded in the preceding week. The 163 deaths in Dablin last week included 21 of infants under one year of age, and 39 of persons aged upwards of sixty years; the deaths both of infants and of elderly persons were below those recorded in any recent week No inquest cases or deaths from violence were registered; and 58 , or more than a third, of the deaths occurred in public institutions. The causes of 14 , or more than 8 per cont., of the deaths in the city last week were not certified. 